\title{
A case of peritoneal dialysis-associated peritonitis caused by Rhodococcus kroppenstedtii
}

\author{
Yi Kang ${ }^{1}$, Yuxin Chen ${ }^{2}$, Zhifeng Zhang ${ }^{2}$, Han Shen², Wanqing Zhou ${ }^{2^{*}}$ (D) and Chao Wu ${ }^{1^{*}}$
}

\begin{abstract}
Background: Rhodococcus kroppenstedtii is an aerobic, gram-positive bacterium firstly identified in the environment, which has not been reported in human-related infection. Herein, we reported the first case of peritoneal dialysis (PD)-associated peritonitis caused by $R$. kroppenstedtii which was identified by whole genome sequencing.

Case presentation: A 69-year-old man was admitted to hospital with abdominal pain and fever. Over the last 2 years, he had been undergoing continuous ambulatory peritoneal dialysis (CAPD) due to end-stage renal disease. Clinical symptom and sign in combination with laboratory examinations supported the clinical diagnosis of PDassociated peritonitis. Thus, ceftizoxime and teicoplanin were empirically used after PD effluent was collected for bacterial culture. A gram-positive bacterium was found from the PD effluent culture, which could not be identified by either Vitek 2 Compact ANC card or matrix-assisted laser desorption/ionization time-of-flight mass spectrometry. The strain was finally confirmed to be $R$. kroppenstedtii by whole genome sequencing (WGS) through the average nucleotide identity (ANI) analysis. With a continuous treatment with teicoplanin and imipenem for 15 days and intraperitoneal catheter removed, the infection symptom was improved evidenced by a normal body temperature, also with white blood cell count (WBC), procalcitonin (PCT) and C-reactive protein (CRP) dropped to normal levels. Peritoneal dialysis effluent culture showed a negative result. Then, hemodialysis and arteriovenous fistula angioplasty were performed, but the patient developed a progressive blood pressure loss, accompanied by multiple organ disorder, and died on Feb 25, 2020.
\end{abstract}

Conclusions: To the best of our knowledge, this is the first time to report a peritoneal dialysis-associated peritonitis caused by $R$. kroppenstedtii which was identified by average nucleotide identity analysis based on WGS.

Keywords: Rhodococcus kroppenstedtii, Peritoneal dialysis-associated peritonitis, Whole genome sequencing, Average nucleotide identity

\footnotetext{
*Correspondence: zwq_096@163.com; dr.wu@nju.edu.cn

${ }^{2}$ Department of Laboratory Medicine, Nanjing Drum Tower Hospital, the Affiliated Hospital of Nanjing University Medical School, Nanjing, Jiangsu Province 210008, P. R. China

${ }^{1}$ Department of Infectious Diseases, Nanjing Drum Tower Hospital, Clinical College of Nanjing Medical University, 321\# Zhongshan Road, Gulou District, Nanjing City, Jiangsu Province 210008, P. R. China
}

(c) The Author(s). 2021 Open Access This article is licensed under a Creative Commons Attribution 4.0 International License, which permits use, sharing, adaptation, distribution and reproduction in any medium or format, as long as you give appropriate credit to the original author(s) and the source, provide a link to the Creative Commons licence, and indicate if changes were made. The images or other third party material in this article are included in the article's Creative Commons licence, unless indicated otherwise in a credit line to the material. If material is not included in the article's Creative Commons licence and your intended use is not permitted by statutory regulation or exceeds the permitted use, you will need to obtain permission directly from the copyright holder. To view a copy of this licence, visit http://creativecommons.org/licenses/by/4.0/ The Creative Commons Public Domain Dedication waiver (http://creativecommons.org/publicdomain/zero/1.0/) applies to the data made available in this article, unless otherwise stated in a credit line to the data. 


\section{Background}

Rhodococci are aerobic, gram-positive, partially acid-fast, catalase-positive, non-motile, non-spore-forming, rodand coccoid-like bacteria which can be isolated from various sources of the environment and usually infect immunocompromised patients such as Acquired Immune Deficiency Syndrome (AIDS) or transplant recipients $[1,2]$. In the past decades, due to the advantage of improved taxonomic methodology, including both chemotaxonomic and molecular based approaches, many species have been established or reclassified and 73 named species (https://lpsn.dsmz.de/genus/rhodococcus) are included in Rhodococci genus. R. equi is the most described human pathogen which causes pneumonia in immunocompromised humans [1-3], while few case reports about Rhodococcus spp. causing peritonitis were reported $[4,5]$. Extrapulmonary infection was reported including brain abscess, complicated skin and soft tissue infection, bloodstream infection, lymphadenitis, and pericarditis $[1,2]$. To the best of our knowledge, Rhodococcus kroppenstedtii, which was firstly isolated in the cold desert of Himalayas, India, has not been previously described as a human pathogen [6]. Herein, we present the first case of peritoneal dialysis (PD)-associated peritonitis caused by $R$. kroppenstedtii which was identified by whole genome sequencing (WGS) and average nucleotide identity (ANI) analysis in China.

\section{Case presentation}

A 69-year-old man was admitted to our hospital on Jan 25, 2020 with a complaint of fever and abdominal pain for 1 days' duration. The patient was diagnosed with hypertension and cerebral infarction 10 years ago, and also with a medical history of renal anemia and cholecystectomy. In 2014, the patient was diagnosed with IgA nephropathy by a renal biopsy and was treated with diet. In 2018, the patient progressed to chronic kidney disease stage 5 and underwent peritoneal dialysis for 2 years until this admission.

At the emergency department on Jan 25, 2020, his physical examination showed a body temperature of $38.6^{\circ} \mathrm{C}$, a blood pressure of $206 / 95 \mathrm{mmHg}$, a pulse rate of 85 beats $/ \mathrm{min}$, and a respiratory rate of 18 breaths/ min. He complained tenderness and rebound pain in his abdomen, with pitting lower extremity edema. Redness or discharge was not found near the peritoneal catheter. Laboratory tests revealed a white blood cell count (WBC) of $13.9 \times 10^{9} / \mathrm{L}$ with $80.7 \%$ neutrophils, a hemoglobin $(\mathrm{Hb})$ level of $74 \mathrm{~g} / \mathrm{L}$, a C-reactive protein (CRP) level of $96.7 \mathrm{mg} / \mathrm{L}$, a procalcitonin (PCT) level of $3 \mathrm{ng} / \mathrm{ml}$, a B-type natriuretic peptide (BNP) level of 939 $\mathrm{pg} / \mathrm{mL}$, an urea level of $25.27 \mathrm{mmol} / \mathrm{L}$ and a creatinine level of $924.2 \mu \mathrm{mol} / \mathrm{L}$. Routine testing of the PD effluent revealed a yellow and muddy appearance with positive results in the Rivalta test, WBC count of $13,363 \times 10^{6} / \mathrm{L}$ (neutrophils: 98\%). Peritoneal dialysis-associated peritonitis was diagnosed initially. The PD effluent was collected for bacterial culture.

Being admitted to the Nephrology ward later in the same day, another PD effluent was collected for bacterial culture before starting an empirical antibiotic therapy. Then, the patient was empirically treated with ceftizoxime intravenously ( $2 \mathrm{~g}$ bid iv) and intraperitoneal injection of teicoplanin (0.2 g qd ip) for 7 days. On Feb 1, a grampositive bacterium was found from PD effluent culture. Therefore, teicoplanin $(0.2 \mathrm{~g}$ qd iv) and imipenem $(0.5 \mathrm{~g}$ qd ip) were administered based on the antimicrobial susceptibility testing for the next 4 days. Due to the low blood concentration of teicoplanin and intraperitoneal catheter removed on Feb 5, the treatment was adjusted to teicoplanin $(0.4 \mathrm{~g}$ qd iv) and imipenem $(0.5 \mathrm{~g}$ q12h iv). With the continuous treatment with teicoplanin and imipenem for 15 days, the infection symptom was improved with a normal body temperature of $36.6^{\circ} \mathrm{C}$, a PCT level of $0.7 \mathrm{ng} / \mathrm{ml}$ and a CRP level of $76.8 \mathrm{mg} / \mathrm{L}$. Routine testing of the peritoneal fluid were within normal ranges. Peritoneal dialysis effluent culture and intraperitoneal catheter culture also showed negative result.

Thereafter, arteriovenous fistula angioplasty was performed for hemodialysis on Feb 15 and the patient developed fever $\left(38^{\circ} \mathrm{C}\right)$ and disturbance of consciousness on the first day after surgery. No cerebral hemorrhage and cerebral infarction were found by cranial Computed Tomography (CT). Considered the toxicity, imipenem was switched to biapenem. However, the patient's symptoms and signs did not improve, and the laboratory test indicators gradually increased. On Feb 17, elevated PCT $(0.801 \mathrm{ng} / \mathrm{mL})$ and CRP $(76.8 \mathrm{mg} / \mathrm{L})$ was observed. Blood culture showed a negative result, and amikacin was given instead of biapenem for the treatment. On Feb 20, the patient still had a fever $\left(37.8^{\circ} \mathrm{C}\right)$ and thick sputum. Laboratory examination revealed a PCT of $1.34 \mathrm{ng} / \mathrm{mL}$, a CRP of $58.5 \mathrm{mg} / \mathrm{L}$, a ESR of more than $140 \mathrm{~mm} / \mathrm{h}$, a $\mathrm{Hb}$ of $45 \mathrm{~g} / \mathrm{L}$. The fecal occult blood test was positive and the blood culture was negative. High resolution CT of the thorax showed inflammatory manifestations including pulmonary cord, flocculent shadow and exudate. Unfortunately, the patient died on Feb 25 due to septic shock and multi-organ failure.

\section{Bacteria culture and identification}

On Jan 25, 2020, twenty milliliters of PD effluent were drawn and injected into aerobic and anaerobic blood culture bottles (bioMérieux, France), and sent to the Bacter/Alter 3D automated blood culture system (bioMérieux, France). At the same time, another ten milliliters of PD effluent were centrifuged for smear with gram-positive bacilli upon gram staining (Baso, Zhuhai, 
China). After culturing for $55 \mathrm{~h}$, a positive signal was observed in the aerobic blood culture bottle, and the culture fluid was directly smeared with gram-positive bacilli which was consistent to the directly smear result before. No bacteria were found in anaerobic medium with $120 \mathrm{~h}$ of culture. After his admission, another ten milliliters of PD effluent were collected into aerobic blood culture bottle on Jan 25 with a positive culture result after $54 \mathrm{~h}$. Positive culture fluid was transferred to Columbia blood agar (OXOID) and incubated at $35^{\circ} \mathrm{C} 5 \% \mathrm{CO}_{2}$. A few small colonies were observed after $24 \mathrm{~h}$ of incubation; $48 \mathrm{~h}$ later, orange-red colonies were observed; with another $24 \mathrm{~h}$ culture, dry, rough, convex and orange-redpigmented was observed. Catalase was produced; acidfast and weakly acid-fast staining were negative. The strain we obtained was named JXM12926.

Biochemical identification of JXM12926 was carried out by using Vitek 2 Compact ANC card (bioMérieux, France) according to the manufacturer' instructions which identified to Acinomyces odontolyticus and Turicella otitidis with $50 \%$ identification rate respectively. Additional testing using the VITEK mass spectrometry v3.0 (bioMérieux, France) failed to identify the strain. Genomic DNA of JXM12926 was prepared using the QIAamp DNA mini kit (Qiagen, Hilden, Germany) and was subjected to whole-genome sequencing using the Ion Torrent Personal Genome Machine (Life Technologies, USA). Library construction, sequencing reactions were performed according to the manufacturer's instructions and a 300 pair-end library was generated. The resulting sequences were de novo assembled using SOAPdenovo v2.01 (http://soap. genomics.org.cn/, v2.01) [7]. For the prokaryotic organism, we used ab initio prediction method to get gene models for strain JXM12926. Gene models were identified using Glimmer 3 [8]. All gene models were then blasted against non-redundant (NR in NCBI) database, SwissProt (http:// uniprot.org), KEGG (http://www.genome.jp/kegg/) [9], and COG (http://www.ncbi.nlm.nih.gov/COG) [10], to do functional annotation. The ANI between JXM12926 and its phylogenetic neighbors was analyzed by the software Orthologous Average Nucleotide Identity Tool (OAT) (http://www.ezbiocloud.net/tools/orthoani), using ncbiblast-2.2.30+ search under the Java Runtime Environment Version 8 [11]. The chromosome comprises 3, 977, $933 \mathrm{bp}$ with a G $+\mathrm{C}$ content of $70.1 \%$ which was similar with $R$. kroppenstedtii DSM 44908. A total of 86 contigs was generated and the N50 contig size was 110, $332 \mathrm{bp}$. By using complete genome sequence, we found a $98.05 \%$ ANI between strain JXM12926 and R. kroppenstedtii DSM 44908. The phylogenetic tree was constructed using the neighbor-joining and Tamura-Nei methods [12] in the software package MEGA 6 (default settings) which was showed in Fig. 1. This whole Genome Shotgun project has been deposited at DDBJ/ENA/GenBank under the accession JACEFU000000000. The version described in this study is version JACEFU010000000.

\section{Antimicrobial susceptibility testing}

Antimicrobial susceptibility testing (AST) was performed using the E-test method on $\mathrm{MH}$ agar (OXOID) including penicillin, ceftriaxone, ceftazidime, imipenem, erythromycin, clindamycin, levofloxacin, vancomycin, and linezolid (Autobio, China) and K-B method including amikacin, tetracycline and sulfamethoxazole (OXOID). The Staphylococcus aureus ATCC29213 and ATCC25923 was included as quality controls. After $48 \mathrm{~h}$ of incubation at $35^{\circ} \mathrm{C}$, strain JXM12926 showed high minimum inhibitory concentration (MIC) value to ceftazidime ( $>256 \mu \mathrm{g} / \mathrm{mL}$ ) while low MICs to penicillin, imipenem, erythromycin, levofloxacin, as showed in Table 1.

\section{Discussion and conclusions}

Rhodococcus species are generally considered as opportunity human pathogens, in which $R$. equi is the most described cause of pheumonia in immunocompromised hosts such as AIDS and transplant recipients $[1,3]$. Besides, other Rhodococcus human pathogens including $R$. bronchialis [13, 14], $R$. rhodochrous [15], $R$. rubropertinctus [16], R. aurantiacus [17], R. rhodnii [17], R. corynebacterioides [18], and $R$. fascians [19] are also reported.

Peritonitis is the main infectious complication in patients undergoing continuous ambulatory peritoneal dialysis (CAPD) in which gram-positive bacteria (60$80 \%$ of all isolates) are the most common pathogens [20]. Bacteria from the skin flora and environmental microbes entering the peritoneal cavity through the catheter is the most common cause of infection [20]. There are few reports of PD-associated peritonitis caused by Rhodocuccus spp., including $R$. equi, R. erythropolis and $R$. bronchialis $[4,5,21-23]$. We report the first clinical PD-associated peritonitis caused by $R$. kroppenstedtii which was identified by WGS and ANI. R. kroppenstedtii was firstly isolated in the cold desert of the Himalayas, India and established in 2006 [6], while no human infectious report as we known.

R. kroppenstedtii could not be identified by Vitek 2 Compact ANC and matrix-assisted laser desorption/ ionization time-of-flight mass spectrometry. Among nucleic acid-based methods, the most powerful approach for revealing reliable phylogenetic relationships is $16 \mathrm{~S}$ rRNA gene sequence analysis, but it failed to differentiate some Rhodococcus species [2]. In 2019, a case of neonatal oligoarthritis and bactermia caused by Rhodococcus which could not be differentiated between $R$. corynebacterioides and $R$. kroppenstedtii by $16 \mathrm{~S}$ rRNA sequence [18], while DNA-DNA hybridization methods is recommended for the delineation of such species [2].

Accurate species-level identification of isolates from clinical specimens is crucial for understanding their 


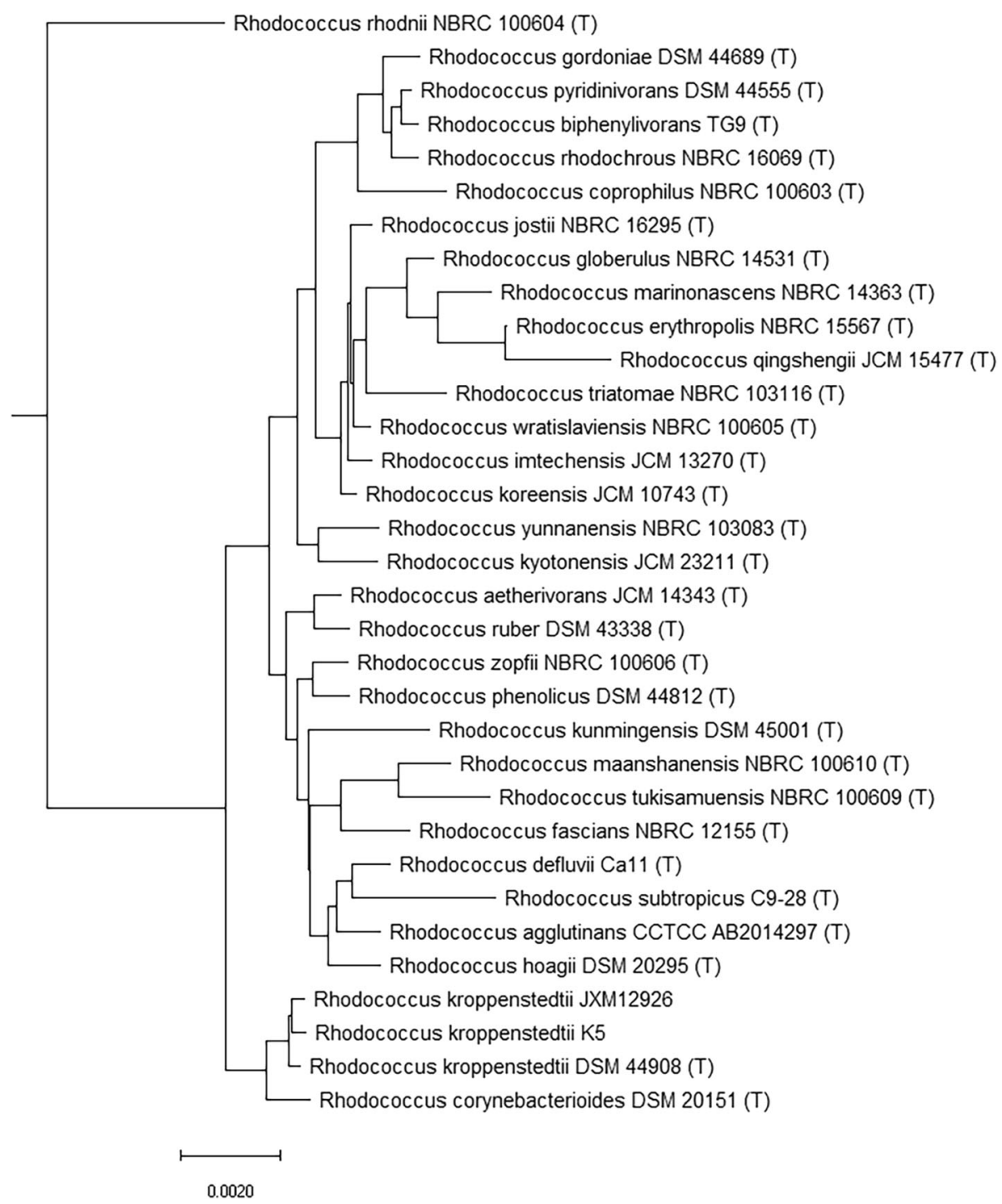

Fig. 1 The phylogenetic tree of Rhodococcus spp. based on the WGS was constructed by neighbor-joining method and kimura 2-parameter model with using the MEGA 6 software. The scale bar shows the genetic distance. The number presented next to each node shows the percentage bootstrap value of 1000 replicates

pathogenesis. Unfortunately, most commercial available detection systems are not capable for the identification of Rhodococcus species, suggesting a potential pitfall in conventional clinical microbiology laboratory. Whole genome sequencing provides the opportunity of a comprehensive understanding for genome of bacteria, which has been widely used for bacterial classification, evolution, and surveillance of antibiotic resistant genes [2]. The average pairwise genome aggregate ANI between genomes with JXM12926 and R. kroppenstedtii DSM 44908 was $98.05 \%$, up the $95 \%$ ANI cutoff frequently used for species demarcation [11], and supporting the classification of JXM12926 into R. kroppenstedtii. The phylogenetic tree constructed by the OrthoANI distance of the whole genome sequence showed that JXM12926 was grouped into the $R$. kroppenstedtii cluster.

Empirical treatment for peritonitis are anti-positive bacteria according International Society for Peritoneal Dialysis (ISPD) guideline [20], while no recommendations for treatment of Rhodococcus-induced peritonitis is included in the guideline. It is reported that macrolide family together with rifampicin are the most effective antibiotic agents for the treatment of Rhodococcus [24]. R. kroppenstedtii JXM12926 in our study shown susceptible to carbapenems, glycopeptides and penicillin. It is suggested that a combination of at least two antimicrobial agents should be used for treatment, including an antibiotic with intracellular activity [2]. Our patient 
Table 1 Antimicrobial susceptibility testing of R. kroppenstedtii strain JXM12926

\begin{tabular}{lll}
\hline Antibiotics & MIC $(\boldsymbol{\mu g} / \mathbf{m L})$ & K-B $(\mathbf{m m})$ \\
\hline Penicillin & 0.5 & \\
Ceftriaxone & 8 & \\
Ceftazidime & $>256$ \\
Imipenem & 0.125 & \\
Erythromycin & 0.25 & \\
Clindamycin & 2 & \\
Levofloxacin & 0.048 & \\
Vancomycin & 0.5 & 32 \\
Linezolid & 1 & 28 \\
Amikacin & & 6 \\
Tetracycline & & \\
Sulfamethoxazole & & \\
\hline
\end{tabular}

initially received intravenous ceftizoxime, intraperitoneal injection of teicoplanin for empirical treatment. Given the drug sensitivity results, the treatment was changed to intravenous teicoplanin and imipenem. Then, the patient rapidly improved. However, after the arteriovenous fistula angioplasty and discontinuation of imipenem, the patient's infection symptoms reappeared. It was uncertain whether the recurrence of infection is related to the previous infection control.

In conclusion, to our knowledge, this is the first case of peritoneal dialysis-associated peritonitis caused by $R$. kroppenstedtii which was identified by average nucleotide identity analysis based on WGS. The identification process for this strain JXM12926 is sufficient to provide a limited data support for the detailed study on this species of $R$. kroppenstedtii.

\section{Abbreviations}

PD: Peritoneal Dialysis; CAPD: Continuous Ambulatory Peritoneal Dialysis; WGS: Whole genome sequencing; ANI: Average nucleotide identity; WBC: White blood cell; PCT: Procalcitonin; CRP: C-reactive protein; AIDS: Acquired Immune Deficiency Syndrome; Hb: Hemoglobin; BNP: B-type natriuretic peptide; CT: Computed tomography; AST: Antimicrobial susceptibility testing; MIC: Minimum Inhibitory Concentration; ISPD: International Society for Peritoneal Dialysis

\section{Acknowledgements}

The authors thank the staff of the laboratory of clinical microbiology of Nanjing Drum Tower Hospital, Nanjing, China, for the culture and identification of clinical microorganism.

\section{Authors' contributions}

KY, ZW and WC performed design, contributed to the acquisition, analysis and interpretation of data and drafted the manuscript. CY assisted in the experiment, analysis and coordination of the project. ZZ and SH participated in strain identification and the WGS analysis. All authors have read and approved the final manuscript.

\section{Funding}

This study was supported by the Nanjing Medical Science and Technique Development Foundation (Grant No. QRX17143, YKK17056). The funders had no role in study design, data collection and analysis, decision to publish, or preparation of the manuscript.

\section{Availability of data and materials}

The datasets used and/or analyzed during the current study are available from the corresponding author on reasonable request. The genome of JXM12926 is available in the DDBJ/ENA/GenBank repository, under the accession JACEFU000000000.

\section{Declarations}

Ethics approval and consent to participate

This study was approved by the Ethics Committee of Nanjing Drum Tower Hospital.

\section{Consent for publication}

Written informed consent was obtained from the patient's family member for publication of this case report.

\section{Competing interests}

The authors declare that they have no competing interests.

Received: 2 December 2020 Accepted: 3 June 2021

Published online: 13 June 2021

References

1. Topino S, Galati V, Grilli E, Petrosillo N. Rhodococcus equi infection in HIVinfected individuals: case reports and review of the literature. AIDS Patient Care STDs. 2010;24(4):211-22. https://doi.org/10.1089/apc.2009.0248.

2. Majidzadeh M, Fatahi-Bafghi M. Current taxonomy of Rhodococcus species and their role in infections. Eur J Clin Microbiol Infect Dis. 2018;37(11):204562. https://doi.org/10.1007/s10096-018-3364-X.

3. Gray KJ, French N, Lugada E, Watera C, Gilks CF. Rhodococcus equi and HIV1 infection in Uganda. J Inf Secur. 2000;41(3):227-31. https://doi.org/10.1 053/jinf.2000.0730.

4. Tang S, Lo CY, Lo WK, Chan TM. Optimal treatment regimen for CAPD peritonitis caused by Rhodococcus species. Nephrol Dial Transplant. 1997; 12(5):1080-1. https://doi.org/10.1093/ndt/12.5.1080.

5. Azzam O, Crowe A, Sajiv C, Pawar B. Rhodococcus equi peritonitis in continuous ambulatory peritoneal dialysis: a first in Australia. BMJ Case Rep. 2015;2015:bcr2014207753. https://doi.org/10.1136/bcr-2014-207753.

6. Mayilraj S, Krishnamurthi S, Saha P, Saini HS. Rhodococcus kroppenstedtii sp. nov., a novel actinobacterium isolated from a cold desert of the Himalayas, India. Int J Syst Evol Microbiol. 2006;56(Pt 5):979-82. https://doi.org/10.1099/ ijs.0.63831-0.

7. Li R, Li Y, Kristiansen K, Wang J. SOAP: short oligonucleotide alignment program. Bioinformatics. 2008;24(5):713-4. https://doi.org/10.1093/ bioinformatics/btn025

8. Delcher AL, Bratke KA, Powers EC, Salzberg SL. Identifying bacterial genes and endosymbiont DNA with glimmer. Bioinformatics. 2007;23(6):673-9. https://doi.org/10.1093/bioinformatics/btm009.

9. Kanehisa M, Goto S, Sato Y, Furumichi M, Tanabe M. KEGG for integration and interpretation of large-scale molecular datasets. Nucleic Acids Res. 2012; 40(D1):D109-14. https://doi.org/10.1093/nar/gkr988.

10. Tatusov RL, Galperin MY, Natale DA, Koonin EV. The COG database: a tool for genome-scale analysis of protein functions and evolution. Nucleic Acids Res. 2000;28(1):33-6. https://doi.org/10.1093/nar/28.1.33.

11. Lee I, Ouk Kim Y, Park SC, Chun J. OrthoANI: an improved algorithm and software for calculating average nucleotide identity. Int I Syst Evol Microbiol. 2016;66(2):1100-3. https://doi.org/10.1099/ijsem.0.000760.

12. Sims GE, Jun SR, Wu GA, Kim SH. Alignment-free genome comparison with feature frequency profiles (FFP) and optimal resolutions. Proc Natl Acad Sci U S A. 2009;106(8):2677-82. https://doi.org/10.1073/pnas.0813249106.

13. Ambesh P, Kapoor A, Kazmi DH, Elsheshtawy M, Shetty V, Lin YS, et al. Sternal osteomyelitis by Gordonia Bronchialis in an immunocompetent patient after open heart surgery. Ann Card Anaesth. 2019;22(2):221-4. https://doi.org/10.4103/aca.ACA_125_18.

14. Chang JH, Ji M, Hong HL, Choi SH, Kim YS, Chung CH, et al. Sternal osteomyelitis caused by Gordonia bronchialis after open-heart surgery. Infect Chemother. 2014;46(2):110-4. https://doi.org/10.3947/ic.2014.46.2.110. 
15. Gopaul D, Ellis C, Maki A Jr, Joseph MG. Isolation of Rhodococcus rhodochrous from a chronic corneal ulcer. Diagn Microbiol Infect Dis 1988; 10(3):185-190. doi: https://doi.org/10.1016/0732-8893(88)90039-9.

16. Hart DH, Peel MM, Andrew JH, Burdon JG. Lung infection caused by Rhodococcus. Aust NZ J Med. 1988;18(6):790-1. https://doi.org/10.1111/j.144 5-5994.1988.tb00182.x.

17. Wilmes D, Coche E, Rodriguez-Villalobos H, Kanaan N. Bacterial pneumonia in kidney transplant recipients. Respir Med. 2018;137:89-94. https://doi.org/1 0.1016/j.rmed.2018.02.022.

18. Khalil N, Corker L, Powell EA, Mortensen JE. Neonatal bacteremia and oligoarthritis caused by Rhodococcus corynebacterioides/Rhodococcus kroppenstedtii. Diagn Microbiol Infect Dis. 2019;94(4):395-7. https://doi.org/1 0.1016/j.diagmicrobio.2019.02.005.

19. Austin MC, Hallstrand TS, Hoogestraat DR, Balmforth G, Stephens K, ButlerWu S, et al. Rhodococcus fascians infection after haematopoietic cell transplantation: not just a plant pathogen? JMM Case Rep. 2016;3(2): e005025. https://doi.org/10.1099/jmmcr.0.005025.

20. ISPD. Peritonitis recommendations: 2016 update on prevention and treatment. Perit Dial Int. 2018;38(4):313. https://doi.org/10.3747/pdi.2018. 00030.

21. Brown $\mathrm{E}$, Hendler $\mathrm{E}$. Rhodococcus peritonitis in a patient treated with peritoneal dialysis. Am J Kidney Dis 1989;14(5):417-418. doi: https://doi. org/10.1016/s0272-6386(89)80177-5.

22. Chow KM, Szeto CC, Chow VC, Wong TY, Li PK. Rhodococcus equi peritonitis in continuous ambulatory peritoneal dialysis. J Nephrol. 2003;16(5):736-9.

23. Hoque $\mathrm{S}$, Weir A, Fluck R, Cunningham J. Rhodococcus equi in CAPDassociated peritonitis treated with azithromycin. Nephrol Dial Transplant. 1996;11(11):2340-1. https://doi.org/10.1093/oxfordjournals.ndt.a027166.

24. Yamshchikov AV, Schuetz A, Lyon GM. Rhodococcus equi infection. Lancet Infect Dis. 2010;10(5):350-9. https://doi.org/10.1016/S1473-3099(10)70068-2.

\section{Publisher's Note}

Springer Nature remains neutral with regard to jurisdictional claims in published maps and institutional affiliations.

Ready to submit your research? Choose BMC and benefit from:

- fast, convenient online submission

- thorough peer review by experienced researchers in your field

- rapid publication on acceptance

- support for research data, including large and complex data types

- gold Open Access which fosters wider collaboration and increased citations

- maximum visibility for your research: over $100 \mathrm{M}$ website views per year

At $\mathrm{BMC}$, research is always in progress.

Learn more biomedcentral.com/submissions 